A C T A C H E I CA S C A N D I N A I C A E (1951) $283-290$

\title{
The Activation of Alkaline Phosphatase from Different Organs by Phosphorylated Vitamin $\mathrm{D}_{2}$
}

\author{
ROLF ZETTERSTRÖM and MARGARETA LJUNGGREN \\ Department of Metabolic Research, Wenner-Gren Institute, Stockholm, Sweden
}

\begin{abstract}
Tn an earlier paper ${ }^{1}$ a method was described of phosphorylating Vitamin $D_{2}$. The phosphorylated compound is soluble in water in concentrations of up to $5 \times 10^{-4} M$. The increase in solubility after phosphorylation makes it possible to investigate the action of Vitamin $\mathrm{D}$ on an in vitro system, which is not possible with substances which are totally insoluble in water. Hitherto it has been possible to study the effect of $\alpha$-tocopherol ${ }^{2-4}$ and certain oestrogenic hormones ${ }^{5}$ on some in vitro systems with the aid of the phosphorylated and in water soluble compounds.

In the following experiments it is shown that phosphorylated Vitamin $\mathrm{D}_{2}\left(\mathrm{D}_{2} \mathrm{P}\right)$ activates alkaline phosphatase from the kidneys, intestines, and bones. This effect of Vitamin $D$ seems to be of interest because of the vitamin's specifically antirachitic mode of action.
\end{abstract}

\section{METHODS}

Crystalline Vitamin $\mathrm{D}_{2}$ (obtained from AB Ferrosan, Malmö) was phosphorylated in accordance with a previously described method ${ }^{1}$. The phosphorylated compound is considerably more sensitive to light than the non-phosphorylated and upon irradiation products are formed with properties differing from those of the original substance. The sensitivity is greatest if the phosphorylated vitamin is kept in a water solution. Absorption in the ultraviolet region, which for $D_{2} P$ reaches a maximum at $2620-2650 \AA$, is shifted toward the shorter wave- lengths at the same time as the coefficient of extinction is reduced. The ability to activate alkaline phosphatase disappears promptly after irradiation.

Alkaline kidney phosphatase of a high degree of purity was prepared from the kidneys of calves in accordance with a modification of Albers' and Albers' 6 method developed by van Thoai, Roche, and Sartori ?. The enzyme contained $10.7 \%$ nitrogen.

Intestinal alkaline phosphatase of a relatively high degree of purity was prepared from the intestines of calves according to Schmidt and Thannhauser ${ }^{8}$. 


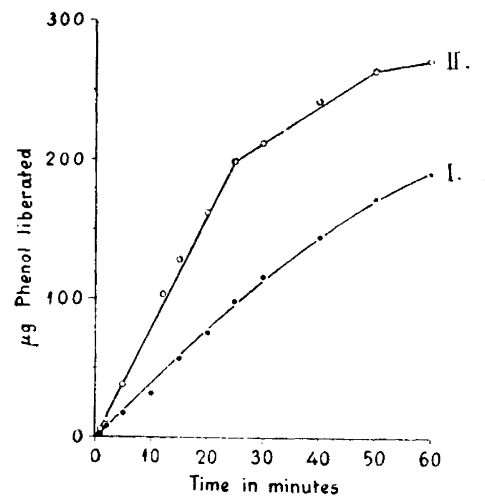

Fig. 1. This figure demonstrates the activation of alkaline kidney phosphatase with phosphorylated Vitamin $D_{2}$. Curve I shows the amount of liberated phenol in an incubation without vitamin. Curve II shows the amount of liberated phenol in an incubation with vitamin. Total volume $12.5 \mathrm{ml}$. Each of the incubation solutions contained $0.25 \mathrm{mg}$ enzyme. $D_{2} P$ concentration $4.8 \times 10^{-5} \mathrm{M}$.

Substrate concentration $6.4 \times 10^{-3} \mathrm{M}$. pH 10.0.

Bone phosphatase was prepared from the bones of rabbits according to Martland and Robison ${ }^{9}$. Since this enzyme was remarkably impure in comparison with phosphatase from the kidneys and intestines, large quantities were required in order to split the substrate. Further purification was nevertheless considered unnecessary, since a noticeable activation of the enzyme was obtained under the influence of $D_{2} P$.

Enzyme activity was determined according to Buch and Buch ${ }^{10}$. Phenylphosphate was used as substrate. The incubations were carried out in a carbonate-tetraborate buffer. At $\mathrm{pH} 10.0$ the concentrations of the buffer substances were $1.8 \times 10^{-2} M$ for sodium carbonate and $2.0 \times 10^{-3} M$ for sodium tetraborate. The temperature in all experiments was $37^{\circ} \mathrm{C}$.

\section{RESULTS}

Fig. 1 shows the effect of the phosphorylated Vitamin $D_{2}$ on the activity of alkaline kidney phosphatase. In incubation without addition of the vitamin, substrate splitting proceeds throughout the experiment as an ordinary enzymatic reaction. After 60 minutes there is no distinct evidence of a decline in the speed of the reaction. The addition of $\mathrm{D}_{2} \mathrm{P}$ changes the course of the reaction. In comparison with the control experiment, there is a considerable increase in the initial enzymatic activity. After 20 minutes twice as much substrate has been split as in the experiment without the addition of the vitamin. Thereafter there begins a period in which the velocity of the reaction is the same as in the control experiment. Finally the curve rather rapidly comes to an asymptote, meaning that a state of equilibrium is reached considerably more quickly in the experiment with the added vitamin than in the control experiment. Presumably the decline in the activity of the phosphatase in the course of the experiment is due to the fact that the total capacity of the enzyme is exhausted more rapidly after the addition of $\mathrm{D}_{2} \mathrm{P}$ than without $\mathrm{D}_{2} \mathrm{P}$. Maximal activation of alkaline kidney phosphatase was not obtained in 
Table 1. Activation of intestinal alkaline phosphatase under the influence of $D_{2} P$.

\begin{tabular}{|r|c|c|c|}
\hline \multirow{2}{*}{ Time } & \multicolumn{2}{|c|}{$\mu$ g Phenol liberated } & Percent \\
& Without $\mathrm{D}_{2} \mathrm{P}$ & With $\mathrm{D}_{2} \mathrm{P}$ & activation \\
\hline 5 min. & 16 & 35 & 119 \\
10 min. & 66 & 85 & 29 \\
20 min. & 86 & 84 & 0 \\
\hline
\end{tabular}

Total volume $5.0 \mathrm{ml}$. The incubation solution contained c. $1 \mathrm{mg}$ enzyme. Substrate concentration $1.5 \times 10^{-3} M$. In the experiment in which $\mathrm{D}_{2} \mathrm{P}$ was added its concentration was $4.3 \times 10^{-5} M$. $\mathrm{pH} 10.0$.

this experiment, since this occurs at $\mathrm{pH}$ about 9.7 and the experiment was carried out at $\mathrm{pH} 10.0$.

Table 1 demonstrates that intestinal alkaline phosphatase is also activated by $\mathrm{D}_{2} \mathrm{P}$. As in the experiment with kidney phosphatase, the activation is greatest during the first minutes and declines thereafter.

The effect of $\mathrm{D}_{2} \mathrm{P}$ on bone phosphatase is shown in Table 2. In both incubations the velocity rate of the enzymatic reaction was relatively low because the enzyme preparation was insufficiently pure. Hence there was no tendency in either of the experiments to diminution of the speed of reaction during the 60 minutes the experiment lasted. Also in this experiment the activation is more pronounced during the first period of incubation. The activation of alkaline bone phosphatase obtained after addition of $\mathrm{D}_{2} \mathrm{P}$ is much higher than for kidney phosphatase.

Table 2. Activation of bone phosphatase under the influence of $D_{2} P$.

\begin{tabular}{|c|c|c|c|}
\hline \multirow{2}{*}{ Time } & \multicolumn{2}{|c|}{$\mu \mathrm{g}$ Phenol liberated } & \multirow{2}{*}{$\begin{array}{c}\text { Percent } \\
\text { activation }\end{array}$} \\
\hline & Without $\mathrm{D}_{2} \mathrm{P}$ & With $\mathrm{D}_{2} \mathrm{P}$ & \\
\hline 15 min. & 13 & 60 & 360 \\
\hline $20 \mathrm{~min}$. & 14 & 68 & 390 \\
\hline $30 \mathrm{~min}$. & 42 & 89 & 110 \\
\hline $45 \mathrm{~min}$. & 68 & 120 & 76 \\
\hline $60 \mathrm{~min}$. & 85 & 135 & 59 \\
\hline
\end{tabular}

The incubations were carried out in the same way as in the preceding experiment. $5 \mathrm{mg}$ impure enzyme to each incubation. Concentration of $\mathrm{D}_{2} \mathrm{P} \times 10^{-5} M$. Substrate concentration $6 \times 10^{-3} \mathrm{M}$. 
Table 3. The effect of varying amounts of $D_{2} P$ on alkaline kidney phosphatase.

\begin{tabular}{|c|c|c|}
\hline \multirow{3}{*}{ Concentration $\mathrm{D}_{2} \mathrm{P}$} & \multicolumn{2}{|c|}{ Percent activation } \\
\cline { 2 - 3 } & Incubated 5 min. & Incubated 10 min. \\
\hline & & 40 \\
$1.17 \cdot 10^{-4} M$ & 54 & 42 \\
$5.75 \cdot 10^{-5} M$ & 54 & 40 \\
$1.17 \cdot 10^{-5} M$ & 21 & 0 \\
$5.75 \cdot 10^{-6} M$ & 0 & 0 \\
$1.17 \cdot 10^{-6} M$ & 0 & $M$ \\
\hline
\end{tabular}

Total volume $3.7 \mathrm{ml}$. The incubation solution contained $80 \mu \mathrm{g}$ enzyme. Substrate concentration $4 \times 10^{-3} M$. pH 8.5.

Table 3 shows the $\mathrm{D}_{2} \mathrm{P}$ concentration required to produce an activation of alkaline kidney phosphatase. The relatively low value for the increase in activity after addition of the phosphorylated vitamin is due to the fact that the incubations were carried out at $\mathrm{pH}$ 8.5. The concentration $5.75 \times 10^{-5} M$ seems to give maximal activation; higher concentrations produce no increase in the activity of the enzyme. At a lower $D_{2} P$ concentration, for example $1.17 \times 10^{-5} M$, the vitamin has given after 10 minutes' incubation the same increase in the amount of hydrolyzed substrate as at higher vitamin concentrations. The low value for the percentual activation after five minutes' incubation would, however, seem to indicate that the concentration was not sufficiently high to produce the initial increase in activity found at higher concentrations. Upon further lowering of the vitamin concentration, $\mathbf{D}_{\mathbf{2}} \mathbf{P}$ completely loses its ability to activate the phosphatase.

Table 4 demonstrates an experiment with bone phosphatase where enzyme concentration was low. In this case the initial activation is less than in

Table 4. The effect of $D_{2} P$ on alkaline bone phosphatase at low enzyme concentration.

\begin{tabular}{|c|c|c|c|}
\hline \multirow{2}{*}{ Time } & \multicolumn{2}{|c|}{$\mu$ g Phenol liberated } & $\begin{array}{c}\text { Percent } \\
\text { activation }\end{array}$ \\
\cline { 2 - 4 } & Without $\mathrm{D}_{2} \mathrm{P}$ & With $\mathrm{D}_{2} \mathrm{P}$ & \\
\hline 15 min. & 10 & 13 & 30 \\
20 min. & 13 & 24 & 85 \\
30 min. & 19 & 43 & 126 \\
\hline
\end{tabular}

The amount of enzyme $2 \mathrm{mg}$ in each incubation. Besides enzyme concentration, the incubations were carried out in the same way as in the preceding experiment with bone phosphatase. 


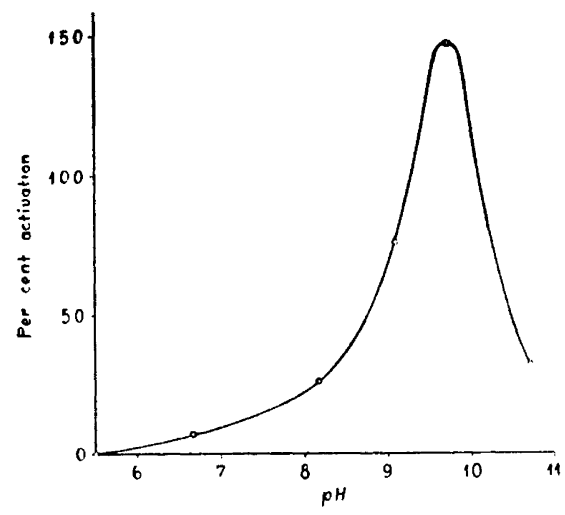

Fig. 2. This figure shows the increase in activity of alkaline kidney phosphatase ob. tained with $D_{2} P$ at different $p H^{\prime} s$. Total volume $3.3 \mathrm{ml}$. $0.2 \mathrm{mg}$ enzyme in each experiment. Substrate concentration $4 \times 10^{-3} \mathrm{M}$. $D_{2} P$ concentration $5.17 \times 10^{-5} M$. Incubation time 10 min.

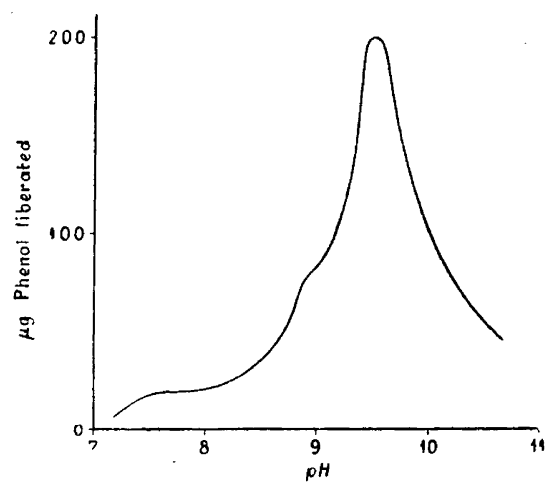

Fig. 3. Activity of alkaline kidney phosphatase at different $\mathrm{pH}^{\prime} \mathrm{s}$. Incubation period 10 min.

experiments with higher enzyme concentrations. The result is the same as when the $\mathrm{D}_{2} \mathrm{P}$ concentration is about $1.17 .10^{-5} M$.

Fig. 2 shows that the extent of the increase in the activity of the alkaline kidney phosphatase produced by $\mathrm{D}_{2} \mathrm{P}$ is manifestly dependent on the hydrogen ion concentration. After 10 minutes' incubation the activation is greatest at $\mathrm{pH}$ 9.7, thus the $\mathrm{pH}$, at which the enzyme itself, according to Fig. 3 reaches its optimal activity. At this optimum $\mathrm{D}_{2} \mathrm{P}$ brings about an increase of c. $150 \%$ in the activity of the enzyme. On either side of this $\mathrm{pH}$ optimum the activation brought about by $\mathrm{D}_{2} \mathrm{P}$. declines with remarkable rapidity. The curve for the increase in activity produced by the vitamin at different hydrogen ion concentrations follows in every respect the curve obtained for the activity of the pure alkaline kidney phosphatase at different $\mathrm{pH}$ 's. This indicates that the increase in activity, to which $\mathrm{D}_{2} \mathrm{P}$ gives rise is specific.

\section{DISCUSSION}

If normal ossification is to take place, the animal must be able to absorb and retain a sufficient amount of phosphate, and this must then be utilized by the bone-forming tissue. In order that as much phosphate as possible may be available for ossification, resorption from the intestines must be high, and renal 
excretion as slight as possible. The loss of phosphate in the urine is probably regulated by an increase or reduction in the reabsorption in the kidney tubules. The greater part of the phosphate which a growing animal retains is used to build up the skeletal system; hence the amount retained must depend primarily on the power of the osteogenic tissue to absorb phosphate and that of the intestinal and tubular epithelium to resorb it. The degree of phosphate resorption from the intestines also depends on the form in which the phosphate occurs. The phosphate compounds must be somewhat soluble in the intestines, and it must be possible to split organic phosphorus compounds.

The absorption of phosphate in a living cell is an active process rather than a simple diffusion ${ }^{11}$. This presupposes a number of enzymatic reactions in which the phosphatases are most probably involved. Robison ${ }^{12}$ has advanced the theory that bone phosphatase is necessary for ossification. If in in vitro experiments with growing bones the phosphatase is inhibited, no precipitation of the bone salts takes place in the metaphysis ${ }^{13}$. Rickets can be induced experimentally by providing rats with beryllium chloride at the same time that their supply of phosphate is diminished ${ }^{14-16}$. In vitro experiments by Sobel and associates ${ }^{16}$ have shown that in beryllium rickets there is a local effect on the bone which hinders calcification. Thus, the etiology of beryllium rickets must involve more than a diminished phosphate resorption from the intestines due to the formation of insoluble beryllium phosphate. Cloetens ${ }^{17}$ has shown that a $10^{-3} M$ solution of beryllium chloride inhibits bone phosphatase. The inhibiting effect of soluble beryllium salts on alkaline kidney phosphatase has been investigated by Klemperer and associates ${ }^{18}$ and on intestinal, bone, and kidney phosphatase by Grier and associates ${ }^{19}$. This inhibition, which is independent of the phosphorus containing substrate, is greatest within the area of the hydrogen ion concentration, where the enzymatic activity is optimal. Therefore, it seems possible that beryllium salts can produce experimental rickets because of their ability to inhibit alkaline phosphatase in the intestines, kidneys, and bones.

Robison ${ }^{20}$ has found that the phosphatase content is higher in the bones of rachitic animals than in those of normal animals. In rickets the alkaline phosphatase in the serum often increases before any other symptoms appear ${ }^{21}$. Upon administration of Vitamin $D$ the serum phosphatase value gradually returns to normal at the same time as other pathological changes disappear ${ }^{22}$. Morris and associates ${ }^{23}$ have assumed that the bones require abnormally large amounts of phosphatase enzyme when there is a Vitamin D deficiency. The increase in the serum phosphatase content should be secondary and conditioned by enzyme from the skeletal system. Vitamin $D$ is necessary for normal ossification; besides regulating the absorption and loss of phosphate, the 
vitamin also has a direct effect on the skeleton itself. It seems possible that the effect of Vitamin D on the phosphate metabolism may be due to an effect on alkaline phosphatase. The changes, which are obtained through administration of Vitamin D, are reactions which can be conditioned by changes in the activity of the alkaline phosphatase. Cohn and Greenberg ${ }^{24}$ have assumed that Vitamin D facilitates the transition from organic to inorganic phosphate and can in this way exert a direct influence on ossification. Vitamin $\mathbf{D}$ undoubtedly influences the resorption of phosphate from the intestines. To a certain extent rats can utilize the phosphate in phytin. Their ability to do this declines considerably if they contract rickets but is rapidly restored after administration of Vitamin $D^{25}$. Harrison and Harrison ${ }^{26}$ have been able to show that the administration of Vitamin $\mathrm{D}$ to rachitic dogs increases the reabsorption of phosphate in the kidney tubules.

If the activation of alkaline phosphatase from the kidneys, intestines, and bones which is obtained in vitro after the addition of $\mathrm{D}_{2} \mathrm{P}$ also occurs in vivo, it is possible that this effect explains the changes in phosphate metabolism which are observed after the administration of Vitamin $D$ to a rachitic animal. The possibilities for phosphate resorption are improved, since the phosphate esters which the intestinal epithelium cannot resorb are more effectively split. There may also be a direct effect on the resorption mechanism in the intestines. The utilization of endogenous phosphate becomes more effective inasmuch as less is lost in the urine. The possibilities for absorption of phosphate by growing bones are improved.

\section{SUMMARY}

1. In vitro, phosphorylated Vitamin $\mathrm{D}_{2}$, which to a certain extent is soluble in water, activates alkaline phosphatase from the kidneys, intestines, and bones. The activation is highest for bone phosphatase. At $\mathrm{pH} \mathrm{10.0,} \mathrm{where} \mathrm{the}$ effect of $\mathrm{D}_{2} \mathrm{P}$ is not optimal, the increase in activity is c. $400 \%$ after 20 minutes incubation time.

2. Optimal activation of alkaline kidney phosphatase is obtained within the hydrogen ion concentration area in which the enzyme has its $\mathrm{pH}$ optimum.

3. The significance of this activation of alkaline phosphatase is discussed with reference to the vitamin's ability to cure rickets.

\section{REFERENCES}

1. Zetterström, R. Nature 167 (1951) 409.

2. Houchin, O. B. J. Biol. Chem. 146 (1942) 313.

3. Ames, S. R. J. Biol. Chem. 169 (1947) 503.

4. Spaulding, M. E., and Graham, W. D. J. Biol. Chem. 170 (1947) 711. 
5. Aldman, B., Diczfalusy, E., and Rosenberg, T. Acta Chem. Scand. 2 (1948) 259.

6. Albers, H., and Albers, E. Z. physiol. Chem. 232 (1935) 189.

7. van Thoai, N., Roche, J., and Sartori, L. Compt. rend. soc. biol. 138 (1944) 47.

8. Schmidt, G., and Thannhauser, S.'J. J. Biol. Chem. 149 (1943) 369.

9. Martland, M., and Robison, R. Biochem. J. 23 (1929) 237.

10. Buch, I., and Buch, H. Acta Med. Scand. 101 (1939) 211.

11. Kamen, M. D., and Spiegelman, S. Cold Spring Harbor Symposia Quant. Biol. 13 (1948) 151.

12. Robison, R. Ergeb. Enzymforsch. 1 (1932) 280.

13. Robison, R., and Rosenheim, A. H. Biochem. J. 28 (1934) 684.

14. Guyatt, B. L., Kay, H. D., and Branion, H. D. J. Nutrition 6 (1933) 313.

15. Jacobson, S. A. Arch. Path. 15 (1933) 18.

16. Sobel, A. E., Goldfarb, A. R., and Kramer, B. J. Biol. Chem. 108 (1935) 395.

17. Cloetens, R. Biochem. Z. 310 (1941) 42.

18. Klamperer, F. W., Miller, J. M., and Hill, C. J. J. Biol. Chem. 180 (1949) 281.

19. Grier, R. S., Hood, M. B., and Hoagland, M. B. J. Biol. Chem. 180 (1949) 289.

20. Robison, R. Biochem. J. 17 (1923) 286.

21. Kay, H. D. Physiol. Revs. 12 (1932) 384.

22. Bodansky, A., and Jaffé, H. L. Arch. Intern. Med. 54 (1934) 88.

23. Morris, N., Stevenson, M. M., Peden, O. D., and Small, J. M. D. Arch. Disease Childhood 12 (1937) 45.

24. Cohn, W. E., and Greenberg, D. M. J. Biol. Chem. 130 (1939) 625.

25. Boutwell, R. K., Geyer, R. P., Halverson, A. W., and Hart, E. B. J. Nutrition 31 (1946) 193.

26. Harrison, H. E., and Harrison, H. C. J. Clin. Invest. 20 (1941) 47.

Received November 14, 1950. 